\title{
Saving those who can't wait
}

\author{
Are Martin Holm ${ }^{1,2}$ and Jens Gottlieb $b^{3,4}$
}

Affiliations: ${ }^{1}$ Dept of Respiratory Medicine, Oslo University Hospital, Oslo, Norway. ${ }^{2}$ Institute of Clinical Medicine, University of Oslo, Oslo, Norway. ${ }^{3}$ Dept of Respiratory Medicine, Hannover Medical School, Hannover, Germany. ${ }^{4}$ Biomedical Research in End-stage and Obstructive Disease (BREATH), German Centre for Lung Research (DZL), Hannover, Germany.

Correspondence: Are Martin Holm, Oslo University Hospital, Dept of Respiratory Medicine, Sognsvannsveien 20, Oslo 0027, Norway. E-mail: a.m.holmamedisin.uio.no

@ERSpublications

For the terminally ill, waiting for a suitable organ for a life-saving transplant may take time. In this issue of the ERJ, the results of the French system for prioritising the urgently ill are reported, and this commentary compares it with other systems. http://bit.ly/2Zw0IaX

Cite this article as: Holm AM, Gottlieb J. Saving those who can't wait. Eur Respir J 2019; 54: 1901668 [https://doi.org/10.1183/13993003.01668-2019].

Lung transplantation is a remarkable accomplishment. It may be the only life-saving treatment option for patients with terminal lung disease, but while some patients may experience a slow progression, others may develop a sudden acceleration and rapid deterioration. The ideal time for the transplantation is therefore not easy to determine. In addition, for a transplant to be possible, the death of another human being is necessary, and the timing of this is inherently unpredictable. Thus, a peculiarity of lung transplantation is that the patients in need are known before the actual treatment is available and it is necessary to create a waiting list.

In an ideal world with plenty of organs for all in need, the management of such a waiting list would not be problematic. Currently, however, the number of patients in need far exceeds the available number of organs, and the proportion of patients dying on the waiting list for lung transplantation is reported to vary from $5 \%$ to $30 \%$ in current allocation systems. Whenever a matching organ becomes available for transplantation, it seems reasonable to allocate the organ to the matching patient on the waiting list who is least likely to survive until the next organ might arrive (rule of rescue) [1]. This means prioritising the most critically ill patients or those who have features suggesting an unacceptably long waiting time, such as an unusual size (usually very small stature) or sensitisation against human leukocyte antigens. While the latter is commonly considered in allocation schemes for kidney transplantation, most lung allocation systems do not take such features into account, possibly due to lower transplant volumes.

The disadvantage of giving unrestricted priority to those most urgently ill is that such patients may often have lower survival rates after transplant. Thus, most urgency allocation schemes include criteria to reduce the rate of possibly futile transplants. Also, if too many patients fulfil the criteria for priority, the system might lose its discriminatory capacity, and a lack of ability to give priority to anyone would ensue [2]. Finally, factors not directly related to urgency may sometimes be included in the allocation scheme, such as geography or recipient age (table 1). Once prioritised, a patient obviously moves upward on the waiting list to the disadvantage of those who consequently are moved down. In some systems, the prioritised patient may additionally get access to organs from a larger procurement area than before. In such cases, the disadvantage for those not prioritised is shared between a higher number of patients at a higher number of collaborating centres (table 1). 
TABLE 1 International urgency criteria in lung transplantation

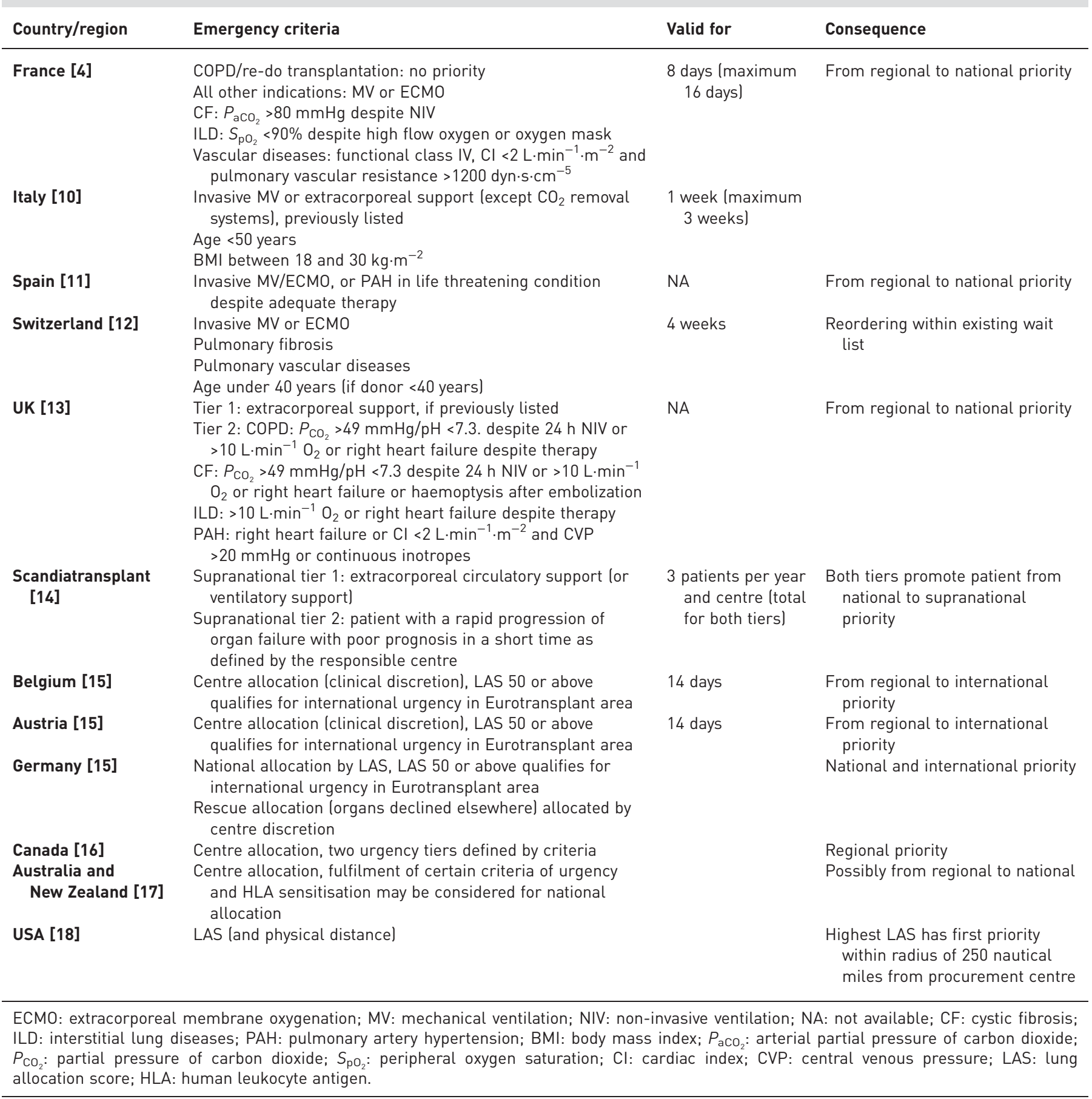

Basically, there are three systems for lung allocation: single centre allocation, national urgency tiers (usually on top of centre allocation), and numerical scoring systems. Single centre allocation means there is just one transplant centre in an organ procurement region. In such systems, whenever an organ becomes available, healthcare professionals select the matching patient on their list perceived to be most needy, usually according to clinical judgment and not according to predefined criteria, although separation into first and second priority tiers according to some criteria may occur. Such centre allocation is used in many countries, especially in countries with only one transplant centre and in systems covering large, sparsely populated areas, such as Canada and Australia. 
An alternative to single centre allocation is urgency allocation that stratifies patients into tiers that give supra-regional priority. This is possible where several centres share one organ procurement system, and the tiers may be determined based on clinical judgment or by specific predefined criteria.

Whether regional or supra-regional, priority may also be determined using a numerical scoring system, such as the Lung Allocation Score (LAS). This is a continuous numerical model based on approximately 20 variables that are assumed to predict survival benefit, and it may be used both for local and supra-regional or international prioritisation [3].

To evaluate whether an allocation system actually works as intended, four basic questions should be answered:

- First, who gets priority? (i.e. are the most imminently urgent patients actually identified by the system, and what other criteria may be at play?)

- Second, is the system efficient? (i.e. does the system ensure allocation of well-matched organs within reasonable time?)

- Third, what is lost? (i.e. does the system reduce the overall survival after lung transplantation?)

- Fourth, what else is affected? (i.e. does the allocation system affect external factors, such as the actual patient selection for lung transplantation, or the number and quality of the organs accepted for transplantation?)

In the current issue of the European Respiratory Journal, Roussel et al. [4] report that since the introduction of the French High Emergency Lung Transplantation system (HELT) in 2007 until the end of the observation period in 2015, 22\% of lung transplant recipients in France were given urgent status. The proportion thus prioritised is substantially higher than the $8 \%$ granted urgent status under the Scandiatransplant scheme [5], where the there is a cap on the number of patients permissible for urgent allocation. In the UK, a criteria-based system of urgency tiers, which is similar to the French system based on a preliminary report after its recent introduction, the number allocated for urgency is similar to the HELT (21\% urgent and 6\% super-urgent) [6]. Translating urgency to a LAS of 50 or above, in Germany this proportion was $28 \%$ [7] while the corresponding proportion is slightly lower in the USA, where $15 \%$ had a LAS >50 in 2017 [8]. It is hard to judge how well the French HELT system actually identifies urgently ill patients since no data about time on waiting list or death on waiting list is given. The defining criteria seem plausible, but it does seem likely that the system also skews the allocation in ways not directly related to urgency, for instance by excluding patients with COPD and by giving preference to younger patients. Interestingly, however, the same tendency seems to be present in other urgency allocation systems (table 2).

The authors did find that the organ matching is stretched in patients allocated by urgency, with more frequent mismatch of size, blood group and cytomegalovirus status, probably with some measurable adverse effects for the recipients. As in an earlier report of the French HELT system [9], Roussel et al. [4] identified a clearly reduced survival in the HELT recipients, with a hazard ratio of death of 1.4 compared

TABLE 2 Results of selected urgency allocation systems

\begin{tabular}{|c|c|c|c|c|}
\hline Country/region & $\begin{array}{l}\text { France (Roussel et al. } \\
\text { [4]] }\end{array}$ & Italy [10] & $\begin{array}{l}\text { Scandiatransplant } \\
{[5]}\end{array}$ & Spain [11] \\
\hline Year of introduction & 2007 & 2010 & 2009 & 1998 \\
\hline Area $\mathrm{km}^{2}$ & 643801 & 301338 & 1320000 & 505990 \\
\hline Centres n & 11 & 10 & 5 & 8 \\
\hline Urgency & $503 / 2333(22 \%)$ & $28 / 140(20 \%)$ & $71 / 1033(7 \%)$ & $279 / 2752(10 \%)$ \\
\hline Urgency tiers $\mathrm{n}$ & 1 & 1 & 2 & 1 \\
\hline Specific criteria & Yes & Yes & No & Yes \\
\hline Waiting time on urgency & NA & 6 days & 3 days & 4 days \\
\hline 1-year death on waiting list urgent/elective & ( $6 \%$ versus $\mathrm{NA})$ & $21 \%$ versus NA & $10 \%$ versus $3 \%$ & $15 \%$ versus NA \\
\hline $\begin{array}{l}1 \text { year survival after lung transplant urgent/ } \\
\text { elective }\end{array}$ & $68 \%$ versus $78 \%$ & $71 \%$ versus NA & $81 \%$ versus $85 \%$ & $\begin{array}{l}61 \% \text { versus } \\
80 \%\end{array}$ \\
\hline
\end{tabular}

ECMO: extracorporeal membrane oxygenation; MV: mechanical ventilation; NA: not available; pmp: per million population. 
to the non-HELT patients. As the authors state, it has to be kept in mind that COPD patients are excluded from these data. The influence the inclusion of these might have had, however, is not reported.

There seems to be reason to believe that the HELT system may have encouraged increased utilisation of donor organs, since the data presented by Roussel et al. [4] also shows that urgently listed patients more frequently receive organs of presumed reduced quality. In an analysis of attributable risks, the authors show that the use of such organs contributed only $4.2 \%$ to the reduced survival of the HELT patients.

There are many very different interests to consider for those who manage the waiting list of potential lung transplantation recipients. In allocation the main motive should be that those who are in need and who have a clear benefit do get a transplant and that no one should be left behind. In times of organ shortage, complex decisions have to be made, and Roussel et al. [4] describe some of the consequences of 8 years of practising the HELT system for lung allocation in France. Many questions remain unanswered, but by publishing their data the authors give tentative answers to some and highlight others. In their discussion, they also provide an ethical context to the decisions that need to be made in urgency allocation. Bringing a patient in need and a suitable donated organ together for lung transplantation is indeed remarkable and the report by Roussel et al. [4] shows some of the complexity of this accomplishment.

Conflict of interest: A.M. Holm has nothing to disclose. J. Gottlieb has nothing to disclose.

\section{References}

McKie J, Richardson J. The rule of rescue. Soc Sci Med 2003; 56: 2407-2419.

Stevenson LW. Crisis awaiting heart transplantation: sinking the lifeboat. JAMA Intern Med 2015; 175: 1406-1409.

Egan TM, Murray S, Bustami RT, et al. Development of the new lung allocation system in the United States. Am J Transplant 2006; 6: 1212-1227.

4 Roussel A, Sage E, Massard G, et al. Impact of donor, recipient, and matching on survival after high emergency lung transplantation in France. Eur Respir J 2019; 54: 1900096.

5 Auraen H, Schultz HHL, Hammainen P, et al. Urgent lung allocation system in the Scandiatransplant countries. J Heart Lung Transplant 2018; 37: 1403-1409.

6 Rushton S, Al-Aloul M, Carby M, et al. The introduction of urgent and super-urgent lung allocation schemes in the United Kingdom. J Heart Lung Transplant 2018; 37: S185.

7 Gottlieb J, Smits J, Schramm R, et al. Lung transplantation in Germany since the introduction of the Lung Allocation Score. Dtsch Arztebl Int 2017; 114: 179-185.

8 Valapour M, Skeans MA, Smith JM, et al. OPTN/SRTR 2015 annual data report: lung. Am J Transplant 2017; 17: Suppl. 1, 357-424.

9 Boussaud V, Mal H, Trinquart L, et al. One-year experience with high-emergency lung transplantation in France. Transplantation 2012; 93: 1058-1063.

10 Palleschi A, Benazzi E, Rossi CF, et al. Lung Allocation Score System: first Italian experience. Transplant Proc 2019; 51: 190-193.

11 Román A, Calvo V, Ussetti P, et al. Urgent lung transplantation in Spain. Transplant Proc 2005; 37: 3987-3990.

12 Swiss Allocation Rules. https://www.swisstransplant.org/de/organspende-transplantation/rechtlichegrundlagen/ Date last accessed: 21 August 2019.

13 UK Allocation Policy. http://odt.nhs.uk/pdf/lung_allocation_policy.pdf Date last accessed: 21 August 2019.

14 Scandiatransplant Allocation Guidelines. http://www.scandiatransplant.org/members/nttr/Guideline_SHLG_oct_ 2017.pdf Date last accessed: 21 August 2019.

15 Eurotransplant Allocation Rules. https://www.eurotransplant.org/cms/mediaobject.php?file=Chapter6_Thoracic13. pdf Date last accessed: 21 August 2019.

16 Hirji A, Zhao H, Lien DC, et al. Clinical judgment vs. Lung Allocation Score in predicting waitlist mortality. J Heart Lung Transplant 2015; 34: S245-S245.

17 Australia and New Zealand Allocation Guidelines. https://www.tsanz.com.au/TSANZ_Clinical_Guidelines Version1.3\%5B6986\%5D.pdf Date last accessed: 21 August 2019.

18 USA OPTN Allocation Rules. https://optn.transplant.hrsa.gov/media/1200/optn_policies.pdf Date last accessed: 21 August 2019. 